\title{
Spinocerebellar ataxia type 34
}

INSERM

\section{Source}

INSERM. (1999). Orphanet: an online rare disease and orphan drug data base.

Spinocerebellar ataxia type 34. ORPHA:1955

Spinocerebellar ataxia type 34 (SCA34) is a subtype of autosomal dominant cerebellar ataxia type I (ADCA type I; see this term), characterized by papulosquamous, ichthyosiform plaques on the limbs appearing shortly after birth and later manifestations including progressive ataxia, dysarthria, nystagmus and decreased reflexes. 